\title{
The Size Dependence of Phytoplankton Growth Rates: A Trade-Off between Nutrient Uptake and Metabolism
}

\author{
Ben A. Ward, ${ }^{1, \star}$ Emilio Marañón, ${ }^{2}$ Boris Sauterey, ${ }^{3,4}$ Jonathan Rault, ${ }^{4}$ and David Claessen ${ }^{4}$ \\ 1. School of Geographical Sciences, University of Bristol, University Road, Bristol BS8 1SS, United Kingdom; 2. Departamento de Ecología \\ y Biología Animal, Universidade de Vigo, 36310 Vigo, Spain; 3. Department of Biology, University of Kentucky, Lexington, Kentucky; \\ 4. Ecole Normale Supérieure, Paris Sciences et Lettres Research University, Institut de Biologie de l'Ecole Normale Supérieure, Centre \\ National de la Recherche Scientifique Unité Mixte de Recherche 8197, Institut National de la Santé et de la Recherche Médicale U1024, \\ 46 Rue d'Ulm, F-75005 Paris, France
}

Submitted August 12, 2016; Accepted October 12, 2016; Electronically published December 12, 2016

Online enhancements: appendixes.

\begin{abstract}
AвSTRACt: Rates of metabolism and population growth are often assumed to decrease universally with increasing organism size. Recent observations have shown, however, that maximum population growth rates among phytoplankton smaller than $\sim 6 \mu \mathrm{m}$ in diameter tend to increase with organism size. Here we bring together observations and theory to demonstrate that the observed change in slope is attributable to a trade-off between nutrient uptake and the potential rate of internal metabolism. Specifically, we apply an established model of phytoplankton growth to explore a trade-off between the ability of cells to replenish their internal quota (which increases with size) and their ability to synthesize new biomass (which decreases with size). Contrary to the metabolic theory of ecology, these results demonstrate that rates of resource acquisition (rather than metabolism) provide the primary physiological constraint on the growth rates of some of the smallest and most numerically abundant photosynthetic organisms on Earth.
\end{abstract}

Keywords: metabolic theory, resource uptake, allometry, power law, unimodal, monomodal.

\section{Introduction}

The maximum growth rate of biological populations $\left(\mu_{\max }\right)$ is an important determinant of community composition and ecosystem function. It constrains both the relative success of species during exponential growth, and the outcome of resource competition when mortality rates are high. The metabolic theory of ecology proposes that the maximum growth rate is controlled by the metabolic rate (Brown et al. 2004), itself limited by fundamental constraints on the distribution

\footnotetext{
* Corresponding author; e-mail: b.a.ward@bristol.ac.uk. ORCIDs: Ward, http://orcid.org/0000-0003-1290-8270; Sauterey, http://orcid .org/0000-0001-6164-756X; Claessen, http://orcid.org/0000-0001-7354-1316.

Am. Nat. 2017. Vol. 189, pp. 170-177. (C) 2016 by The University of Chicago. 0003-0147/2017/18902-57172\$15.00. All rights reserved. DOI: $10.1086 / 689992$
}

of resources within organisms (West et al. 1997; Banavar et al. 2002). These are argued to be such that temperature-corrected rates of metabolism and population growth should vary with cell volume, $V$, as a simple power-law function of the form $\mu_{\max }=a V^{b}$ (i.e., a linear relationship between $\log \left(\mu_{\max }\right)$ and $\log (V))$. The intercept, $a$, gives the maximum growth rate at $V=1 \mu \mathrm{m}^{3}$, while the exponent, $b$, describes the slope of $\log \left(\mu_{\max }\right)$ as a function of $\log (V)$, with a predicted value of -0.25 (West et al. 1997). This prediction for the population growth rate has been confirmed across a broad range of organisms, spanning more than 12 orders of magnitude in body mass (Fenchel 1973; Blueweiss et al. 1978; Peters 1983; Savage et al. 2004). Mounting empirical evidence suggests, however, that maximum growth rates deviate from the predicted monotonic power-law relationship among unicellular organisms smaller than approximately $10 \mu \mathrm{m}$ in diameter (DeLong et al. 2010; Kempes et al. 2012). Among the phytoplankton in particular, a number of studies have observed that maximum population growth rates show a unimodal size dependence, with a peak somewhere in the 2-20- $\mu \mathrm{m}$-diameter size range (Raven 1994; Bec et al. 2008; Chen and Liu 2010; Finkel et al. 2010; Marañón et al. 2013). An example of this unimodal size dependence is shown in figure 1.

It is important that we understand these deviations from the metabolic theory of ecology, because microbial organisms are central to the function of marine communities and the Earth system. Marine plankton are responsible for approximately half of global net primary production (Field et al. 1998) and form the foundation of all pelagic ecosystems. In this capacity, they support essential nutrition to more than half the world's population via fisheries (Hollowed et al. 2013) and play a critical role in maintaining the Earth's climate at a habitable level (Hain et al. 2014). Organism size is an important aspect of these large-scale ecological and biogeochemical processes (Falkowski and Oliver 2007), and a number of theoretical explanations have been put forward to explain 


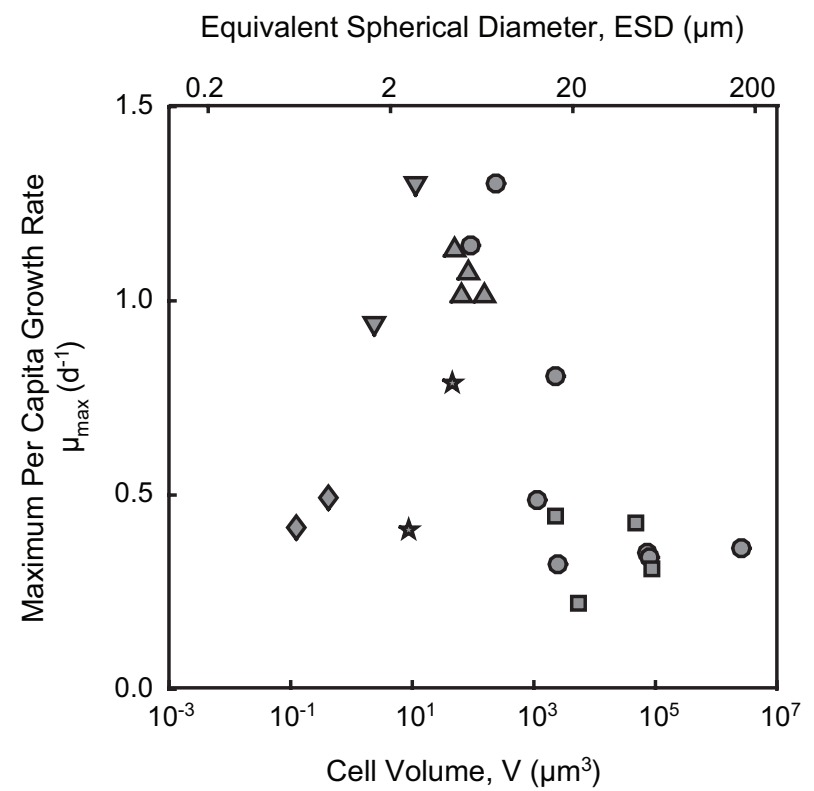

Figure 1: Experimentally observed size dependence of the maximum per capita population growth rate $\left(\mu_{\max }\right)$ in experiments reported by Marañón et al. (2013). Note that these data represent the net phytoplankton growth rate, as calculated in appendix A (available online). Diamond, cyanobacteria; down-pointing triangle, chlorophyte; star, other; up-pointing triangle, coccolithophore; circle, diatom; square, dinoflagellate.

the unimodal pattern seen in figure 1. These have focused variously on nutrient storage capacity (Verdy et al. 2009), resource distribution within the cell (Wirtz 2011), mortality (Kempes et al. 2012), exudation (Kriest and Oschlies 2007), and thermal adaptation (Sal et al. 2015). Empirical support for these theories has, however, typically come from metaanalysis of compiled data rather than from direct experimental tests. It has therefore been difficult to assess the validity of these competing ideas.

In this article, we use observations derived from a single set of experiments (using the same laboratory protocols; Marañón et al. 2013) to explore the pattern shown in figure 1. We will apply these observations within a formal mathematical framework (Burmaster 1979) to show that the observed unimodal size dependence of $\mu_{\max }$ is attributable to a sizedependent trade-off between metabolism and nutrient uptake (Marañón et al. 2013; Marañón 2015). In this way, we will present a simple, mechanistic explanation of why phytoplankton population growth rates deviate from the metabolic theory of ecology at very small size.

\section{Phytoplankton Growth Model}

We wish to assess the idea that the size dependence of the maximum population growth rate is dictated by the balance of nutrient uptake and metabolism (Marañón et al. 2013; Marañón 2015). We therefore apply a phytoplankton growth model that considers both these processes (Caperon 1968; Droop 1968). The model assumes that the per capita population growth rate $(\mu)$ is set as a hyperbolic function of the cellular nutrient quota (Q). Following Burmaster (1979) and consistent with the measurements of Marañón et al. (2013), we define the cell quota in terms of nitrogen biomass per cell. Net population growth requires a quota in excess of the basal cellular nutrient requirement $\left(Q_{\min }\right)$ and increases with increasing $Q$ toward a theoretical maximum metabolic rate, $\mu_{\infty}$. This is effectively the maximum possible rate of cell division assuming an infinite (and unobtainable) internal nutrient reserve (Caperon 1968; Droop 1968):

$$
\mu=\mu_{\infty}\left(1-\frac{Q_{\min }}{Q}\right)
$$

The cellular nutrient quota itself is supplied by nutrient uptake $(\rho)$ and is diluted as cells divide $(\mu Q)$. The rate of change in $Q$ is therefore given by

$$
\frac{\mathrm{d} Q}{\mathrm{~d} t}=\rho-\mu Q
$$

Nutrient uptake is typically assumed to be a saturating (Michaelis-Menten-like) function of environmental nutrient availability. In this study, we are concerned with only periods of nutrient-saturated growth, and so we assume that nutrient uptake is equal to the maximum saturated rate $\left(\rho=\rho_{\max }\right)$. For the sake of simplicity, we ignore the possibility that nutrient uptake is downregulated as the cell quota approaches a maximum capacity. While this mechanism can be important in terms of regulating the size of the nutrient quota when the maximum uptake rate is large relative to the growth rate (Grover 1991), we show in appendix B (apps. A, $\mathrm{B}$ are available online) that accounting for the maximum quota has a negligible impact on the size dependence of the maximum per capita growth rate $\left(\mu_{\max }\right)$.

We assume that nutrient uptake is balanced by cell division during nutrient-saturated exponential growth, such that equation (2) can be rewritten as $\rho_{\max }=\mu_{\max } Q$. This equality can then be substituted into equation (1) to obtain an expression for the maximum phytoplankton growth rate as a function of the three physiological trait parameters (Burmaster 1979):

$$
\mu_{\max }=\frac{\mu_{\infty} \rho_{\max }}{\mu_{\infty} Q_{\min }+\rho_{\max }} .
$$

This equation demonstrates that the maximum phytoplankton growth rate is a composite trait that emerges through the interaction of more fundamental traits relating to biomassspecific nutrient uptake and metabolism. The influence of each fundamental trait on the maximum growth rate is best understood by considering equation (3) in two key limits. In 
the first limit, the maximum rate of nutrient uptake $\left(\rho_{\max }\right)$ is assumed to be much slower than the maximum potential rate of cellular metabolism $\left(\mu_{\infty} Q_{\min }\right)$, and equation (3) can be approximated by

$$
\mu_{\max } \approx \frac{\rho_{\max }}{Q_{\min }} \text { if } \rho_{\max } \ll \mu_{\infty} Q_{\min } .
$$

In this limit, the maximum growth rate is effectively set by the maximum rate at which the basal cellular nutrient requirement $\left(Q_{\min }\right)$ can be replenished by nutrient uptake $\left(\rho_{\max }\right)$. Alternatively, the second limit assumes that $\rho_{\max }$ is much faster than $\mu_{\infty} Q_{\min }$, and equation (3) can be approximated by

$$
\mu_{\max } \approx \mu_{\infty} \text { if } \rho_{\max } \gg \mu_{\infty} Q_{\min } .
$$

In this limit, the maximum growth rate is set by the maximum metabolic rate $\left(\mu_{\infty}\right)$. We will use these fundamental limits to illustrate how the two key rates change in importance as a function of phytoplankton size.

\section{Observations}

Marañón et al. (2013) measured the population growth of 22 species of phytoplankton, spanning a size range of $0.6-$ $168 \mu \mathrm{m}$ equivalent spherical diameter (ESD; 0.1-2.5 $\times 10^{6}$ $\mu \mathrm{m}^{3}$ by volume). The growth of each species was assessed individually in batch cultures, with population size recorded in terms of cell abundance, particulate organic nitrogen, and particulate organic carbon. Marañón et al. (2013) estimated the maximum phytoplankton growth rate $\left(\mu_{\max }\right)$ as the linear rate of change in the natural logarithm of cell abundance at the peak of the exponential phase. Here, $\mu_{\max }$ was estimated by fitting a time-dependent sigmoidal function to the natural logarithm of cell abundance (see app. A). The advantage of this approach is that it uses all the cell abundance data collected throughout each culture experiment and is free from subjective decisions as to when the exponential phase occurs (Zwietering et al. 1990). The use of cell abundance data is consistent with the units of the model, but these data were found to be unreliable in four cultures (Melosira numoloides, Thalassiosira rotula, Coscinodiscus radiatus, and Coscinodiscus wailesii). For these species, $\mu_{\max }$ was instead calculated by fitting the sigmoidal function to the natural logarithm of particulate organic carbon (app. A).

Cellular nitrogen quotas $(Q)$ were determined throughout the batch culture experiments by dividing the concentration of particulate organic nitrogen by the cell abundance. The minimum quota $\left(Q_{\min }\right)$ for each species was determined simply as the smallest cellular quota recorded throughout the duration of each experiment. It should be noted that these values may significantly overestimate the size of the minimum quota in some cases. This is because cells can often metabolize stored nutrients during short periods of nutrient scarcity (Litchman et al. 2009), and the transient nature of the batch culture experiments makes it difficult to assess whether this reserve has been fully exhausted (see "Discussion").

The maximum nitrogen uptake rate $\left(\rho_{\max }\right)$ was determined for nutrient-starved cells as the maximum per capita rate at which nitrogen was removed from the culture medium. This was determined over short experimental periods of $\leq 45 \mathrm{~min}$ in order to capture any short periods of rapid nutrient uptake.

The maximum potential metabolic rate $\left(\mu_{\infty}\right)$ is not directly observable. Instead, we can rearrange equation (3) to estimate $\mu_{\infty}$ from the directly observed values of $\mu_{\max }, \rho_{\max }$, and $Q_{\text {min }}$ :

$$
\mu_{\infty}=\frac{\mu_{\max } \rho_{\max } / Q_{\min }}{\rho_{\max } / Q_{\min }-\mu_{\max }} .
$$

Note that this estimate can become increasingly sensitive to small measurement errors when $\mu_{\max } \approx \rho_{\max } / Q_{\min }$ (i.e., eq. [4]). We show later that this issue is most apparent among smaller cells, for which $\mu_{\infty}$ has very little influence on $\mu_{\max }$. For three of the smallest species, observed values of $\mu_{\max }$ actually exceeded $\rho_{\max } / Q_{\min }$, and a meaningful solution to equation (6) could not be obtained. All data used to constrain the model are reported in appendix A.

\section{Parameterization}

Figure 2 indicates that the three fundamental model parameters $\left(\rho_{\max }, Q_{\min }\right.$, and $\left.\mu_{\infty}\right)$ all show a clear linear relationship with cell volume, $V$, when plotted on logarithmic axes. They can, therefore, be well described by power-law functions of the form $p=a V^{b}$ (where $p$ is the parameter value). The initial values (and associated 95\% confidence intervals) for coefficients $a$ and $b$ were found for each parameter by reduced major axis regression. The coefficients yielded at this first stage are hereafter referred to as the initial estimates.

The initial estimates were subsequently adjusted within their $95 \%$ confidence limits in order to maximize the fit of equation (3) to observations of $\mu_{\max }$. This was done using lsqcurvefit, a nonlinear least squares curve-fitting package in Matlab 2015a. The coefficient values after this second stage are hereafter referred to as the adjusted estimates.

\section{Results}

Power-law functions describing the size dependence of the three model parameters are shown in figure 2. Dashed lines represent the initial estimates, while solid lines represent the adjusted estimates that maximize the fit of equation (3) to observed values of $\mu_{\max }$. The initial and adjusted estimates (and associated 95\% confidence intervals) for coefficients $a$ and $b$ are given in table 1 . It should be noted that two of 

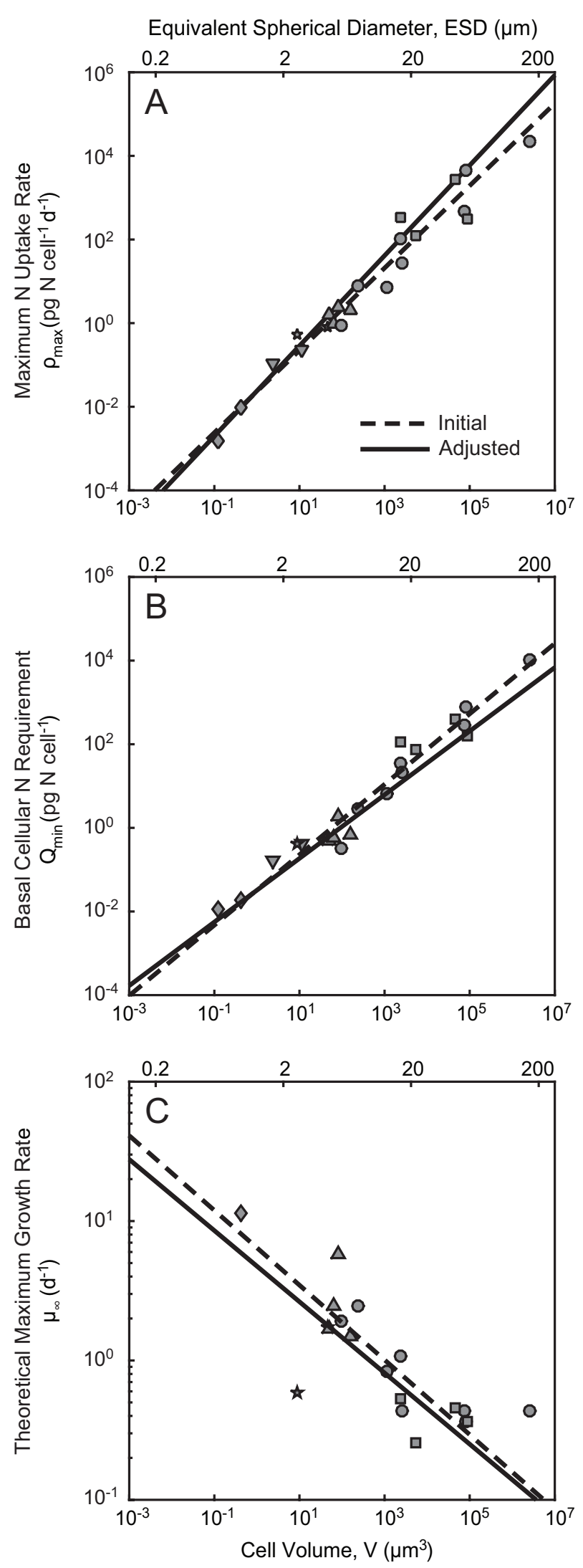

the six coefficients took values at the extremes of their initial confidence limits. This issue is addressed in the discussion.

Figure 3 shows the initial and adjusted fit of equation (3) to observed values of $\mu_{\max }$. The initial fit captures the unimodal shape of the data but underestimates the negative slope of the curve in the sub $\sim 6 \mu \mathrm{m}$ ESD size range. This issue was resolved by the adjustment step, which allowed the model to more accurately reproduce the observed $\mu_{\max }$ data, improving the coefficient of determination $\left(R^{2}\right)$ from 0.56 to 0.64 .

\section{Limiting Factors}

The theoretical model predicts that the maximum growth rate $\left(\mu_{\max }\right)$ is set either by the maximum nutrient uptake rate relative to the basal nutrient requirement $\left(\rho_{\max } / Q_{\min }\right.$; eq. [4]) or by the maximum metabolic rate $\left(\mu_{\infty}\right.$; eq. [5]). We assess this possibility here using output from the adjusted model. Figure $4 A$ shows the model size dependences of $\mu_{\max }$ and $\rho_{\max } / Q_{\min }$, alongside observations of $\rho_{\max } / Q_{\min }$. Both the model and data suggest that the maximum population growth rate among smaller cells is set by the maximum nutrient uptake rate relative to the basal nutrient requirement as an increasing function of organism size. Among cells larger than $\sim 6 \mu \mathrm{m}$ ESD, however, $\mu_{\max }$ falls increasingly below $\rho_{\max } / Q_{\min }$. This suggests that some other factor limits the maximum growth rate of the larger organisms. Figure $4 B$ shows the modeled size dependences of $\mu_{\max }$ and $\mu_{\infty}$ alongside the indirect empirical estimates of $\mu_{\infty}$. Here the model and data suggest that with increasing size, the declining maximum metabolic rate takes over as the primary constraint on the maximum population growth rate.

\section{Discussion}

The metabolic theory of ecology predicts that population growth rates should increase universally with decreasing organism size (Brown et al. 2004). However, this prediction is refuted among the smallest and most abundant organisms. Observations have shown that maximum growth rates among prokaryotes and some very small unicellular eukaryotes actually decrease with decreasing organism size (Kempes et al. 2012; Marañón et al. 2013). This deviation

Figure 2: Size dependence of the model parameters: maximum nutrient uptake rate, $\rho_{\max }(A)$; minimum nutrient quota, $Q_{\min }(B)$; and growth rate at infinite quota, $\mu_{\infty}(C)$. Note that $\mu_{\infty}$ could not be estimated for three smaller taxa (see "Observations"). In each plot, dashed lines show the initial relationships yielded when fitting the powerlaw functions directly to the plotted data. Solid lines show the adjusted estimates derived by fitting equation (3) to the observed values of $\mu_{\max }$ (see table 1 and "Parameterization"). Diamond, cyanobacteria; downpointing triangle, chlorophyte; star, other; up-pointing triangle, coccolithophore; circle, diatom; square, dinoflagellate. 
Table 1: Initial and adjusted power-law coefficients for each parameter shown in figure 2, with 95\% confidence limits for the initial estimates

\begin{tabular}{|c|c|c|c|c|c|c|c|}
\hline \multirow[b]{2}{*}{ Parameter $a V^{b}$} & \multirow[b]{2}{*}{ Units } & \multicolumn{2}{|c|}{ Initial estimates } & \multicolumn{2}{|c|}{$95 \%$ confidence limits } & \multicolumn{2}{|c|}{ Adjusted estimates } \\
\hline & & $a$ & $b$ & $a$ & $b$ & $a$ & $b$ \\
\hline$\rho_{\max }$ & pg $\mathrm{N}$ cell $^{-1}$ day $^{-1}$ & .023 & .98 & $.013-.042$ & $.89-1.10$ & .024 & 1.10 \\
\hline$Q_{\min }$ & pg $\mathrm{N}$ cell $^{-1}$ & .033 & .84 & $.020-.054$ & $.76-.93$ & .032 & .76 \\
\hline$\mu_{\infty}$ & day $^{-1}$ & 6.40 & -.27 & $3.6-12.0$ & -.35 to -.18 & 4.7 & -.26 \\
\hline
\end{tabular}

Note: In each case, $a$ gives the value of the parameter at $V=1 \mu \mathrm{m}^{3}$, while $b$ describes the slope of the log-transformed parameters as functions of log $(V)$. Note that the adjusted exponents $(b)$ of $\rho_{\max }$ and $Q_{\min }$ took values at the extremes of their initial confidence limits.

from the metabolic theory of ecology appears to apply universally to both autotrophic and heterotrophic organisms (DeLong et al. 2010) but was examined here using an important group of photosynthetic unicellular organisms.

Among this group of marine phytoplankton, Marañón et al. (2013) showed that maximum growth rates tend to decline on either side of a peak at $\sim 6 \mu \mathrm{m}$ ESD. We have used a simple and well-established model of phytoplankton growth (Droop 1968; Burmaster 1979) to show that this pattern is attributable to a size-dependent conflict between fundamental physiological traits. The maximum nutrient uptake rate relative to the basal nutrient requirement $\left(\rho_{\max } / Q_{\min }\right)$ scales positively with size. In contrast, the theoretical maximum metabolic rate $\left(\mu_{\infty}\right)$ scales negatively with size. At $\sim 6 \mu \mathrm{m}$

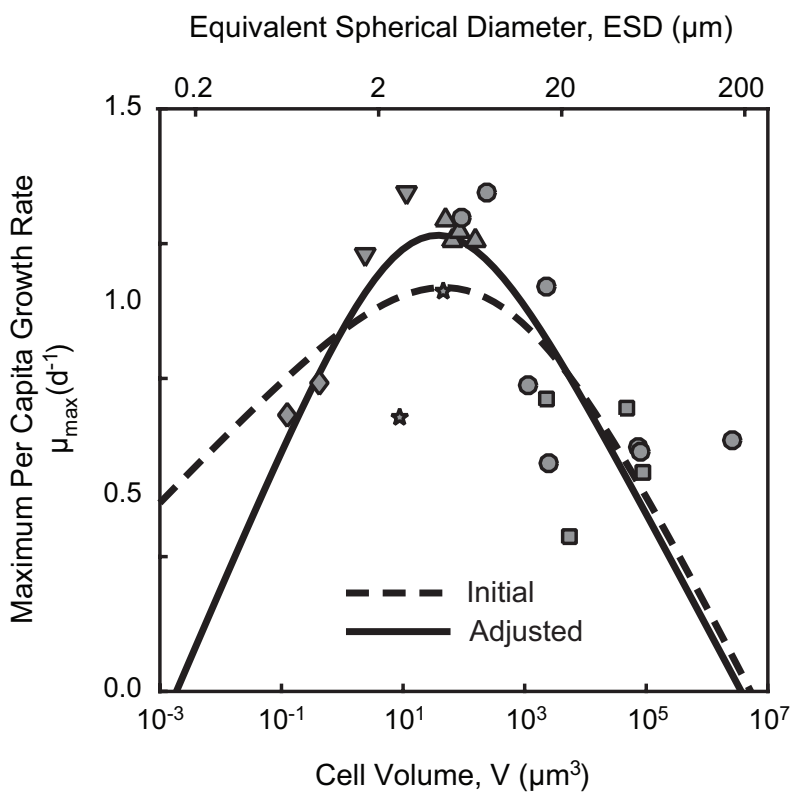

Figure 3: Initial and adjusted estimates of $\mu_{\max }$ given by equation (3) Symbols show the same observational data as in figure 1. Diamond, cyanobacteria; down-pointing triangle, chlorophyte; star, other; uppointing triangle, coccolithophore; circle, diatom; square, dinoflagellate.
ESD, the two rates converge, such that $\mu_{\max }$ among smaller cells is set by the rate at which the internal quota can be replenished by nutrient uptake, while $\mu_{\max }$ among larger cells is limited by the rate at which the internal nutrient quota can be converted into new biomass.

The observed fundamental traits that underpin $\mu_{\max }$ conform to simple allometric power laws (table 1; fig. 2). These can be compared with theoretical predictions. In conjunction with the model, the directly observed traits imply a size-dependent slope for $\mu_{\infty}$ of $-0.27 \pm 0.09$, not significantly different from the value of -0.25 that is predicted by the metabolic theory of ecology. When the model parameters were further adjusted to observations of $\mu_{\max }$, the slope for $\mu_{\infty}$ moved even closer to theory, taking a value of -0.26 . The size dependence of $\mu_{\infty}$, which can be thought of as representing the maximum potential metabolic rate, is therefore consistent with the predictions of the metabolic theory of ecology.

At the other end of the size spectrum, the positive relationship between the maximum growth rate and cell size is not consistent with the metabolic theory of ecology. We have shown that the increasing trend is driven by a sizedependent increase in the maximum nutrient uptake rate relative to the minimum nutrient quota $\left(\rho_{\max } / Q_{\min }\right)$, with a combined exponent of 0.34 . It should be noted that this high value is dependent on adjusted exponents for $\rho_{\max }$ and $Q_{\min }$ that are at the upper and lower extremes, respectively, of their initial confidence intervals (table 1). This raises some concern about the validity of the model, but it is likely that both adjusted exponents are compensating for a probable bias in the initial estimate for the exponent of $Q_{\min }$. This bias occurs because transient batch culture experiments tend to overestimate the size of the minimum quota among larger cells with increased capacity for nutrient storage. A more accurate way to evaluate $Q_{\min }$ is to grow cultures in chemostats with very low nutrient supply rates. Such experiments were performed for Synechococcus $(\sim 0.9 \mu \mathrm{m})$, Emiliania huxleyi $(\sim 7 \mu \mathrm{m})$, and Skeletonema costatum $(\sim 8 \mu \mathrm{m})$ under conditions that were otherwise equivalent to the Marañón et al. (2013) batch culture experiments (E. Marañón, unpublished data). It was found that the original experiments overestimated $Q_{\min }$, more strongly in the larger cells (by $11 \%, 22 \%$, and $55 \%$, respec- 
Equivalent Spherical Diameter, ESD $(\mu \mathrm{m})$

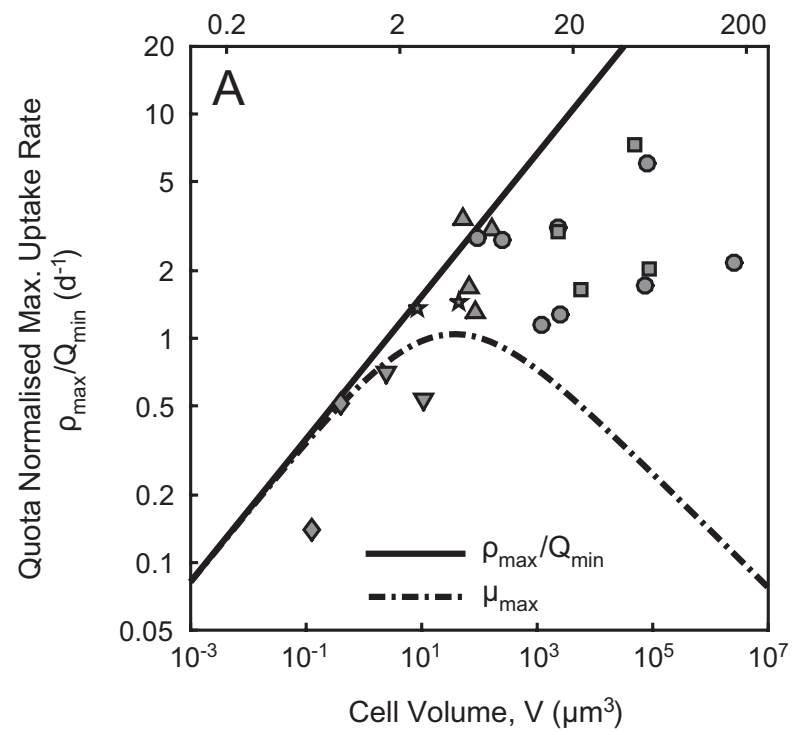

Equivalent Spherical Diameter, ESD $(\mu \mathrm{m})$

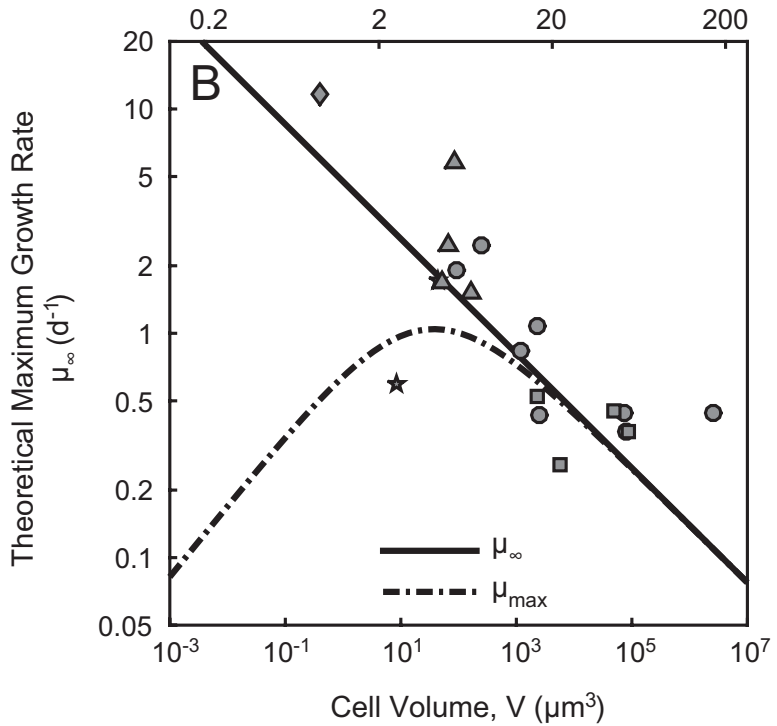

Figure 4: Factors constraining $\mu_{\max }$. Dot-and-dash lines show the adjusted model estimate of $\mu_{\max }$ given by equation (3). In $A$, the solid line indicates the adjusted model size dependence of $\rho_{\max } / Q_{\min }$. In $B$, the solid line indicates the adjusted model size dependence of $\mu_{\infty}$. Note that while the symbols in $A$ represent direct observations, the symbols in $B$ represent model-derived estimates for $\mu_{\infty}$, as given by equation (6). Diamond, cyanobacteria; down-pointing triangle, chlorophyte; star, other; up-pointing triangle, coccolithophore; circle, diatom; square, dinoflagellate.

tively). As a consequence of this bias, the initial estimate for the slope of $Q_{\min }$ is likely too high, causing the adjustment step to choose values at the bottom of the initial range for $Q_{\min }$ and at the top of the initial range for $\rho_{\max }$. We examined the plausibility of this argument by repeating the analysis, excluding all $Q_{\min }$ data for cells larger than $6 \mu \mathrm{m}$. In this case, the initial range for the exponent of $Q_{\min }$ was considerably lower, and the adjusted exponents of $Q_{\min }$ and $\rho_{\max }$ were well within the initial confidence intervals (and within $\sim 1 \%$ the initial best estimates; see table B1; tables $\mathrm{A} 1, \mathrm{~B} 1$ are available online). Perhaps more importantly, the omission of the potentially biased $Q_{\min }$ data had almost no effect on the adjusted fit of equation (3) to the $\mu_{\max }$ data (fig. B1B; figs. A1, B1 are available online), and the adjusted slope of $\rho_{\max } / Q_{\min }$ was almost unchanged at 0.32 . This suggests that the positive slope of $\rho_{\max } / Q_{\min }$ is robust to the likely overestimation of $Q_{\min }$ among the larger cells.

Leaving these issues aside, the positive slope for $\mu_{\max }$ among the smallest phytoplankton is dependent on $Q_{\min }$ increasing less rapidly with cell volume than $\rho_{\max }$. Regardless of the data used, the slope of $Q_{\min }$ was found to have an exponent of $<1$, approximately in line with previous estimates of 0.77 (Litchman et al. 2007) and 0.88 (Edwards et al. 2012). These low values are not surprising because of the increasing proportion of essential and nonscalable nitrogenous components (such as the genome and cellular membranes) in smaller cells (Raven 1994). On the other hand, we found the exponent of $\rho_{\max }$ to be either approximately equal to or greater than 1 . These high values were not expected, because previous meta-analyses and theoretical arguments (based on consideration of the surface area to volume ratio) have suggested a slope of $2 / 3$ (or slightly higher when accounting for nonspherical shapes among larger cells; Litchman et al. 2007; Edwards et al. 2012). The data used in this study - derived from a single set of experiments performed under identical laboratory conditionsindicate that $\rho_{\max }$ scales as an approximately isometric (i.e., linear) function of cell volume (Marañón et al. 2013). This appears to be related to a size-dependent increase in the maximum rate of nutrient uptake per unit of cellular surface area (Marañón et al. 2013), although the underlying cause of this increased uptake capacity remains an open question. Further experimental work will therefore be required to explore the isometric scaling of $\rho_{\max }$, which appears essential to the observed unimodal size dependence of $\mu_{\max }$.

In conclusion, we have used laboratory measurements and an established model of phytoplankton growth to show that the unimodal size dependence of the maximum growth rate is attributable to a size-dependent trade-off between resource acquisition and the maximum metabolic rate. Contrary to the metabolic theory of ecology, the rate at which the internal nutrient quota can be replenished by nutrient uptake appears to be the primary constraint on the maximum growth rates of the smallest and most abundant pho- 
tosynthetic organisms in the ocean. Our analysis provides a new mechanistic framework to understand an important physiological trade-off and should inspire further experimental work that will help to clarify the overarching rules that govern the size-dependent physiology of phytoplankton and other microbial organisms.

\section{Acknowledgments}

We would like to thank S. Hall for his patient efforts during the review process. His detailed and constructive comments have helped to greatly improve the clarity and accessibility of the finished article. We would also like to thank two anonymous reviewers, whose comments led to an improved overall analysis. B.A.W. gratefully acknowledges support from the Past Links in the Evolution of Ocean's Global Environment and Ecology (PALEOGENiE) project (ERC-2013-CoG617313) and thanks the Marine Systems Modelling group at the National Oceanography Centre, Southampton. E.M. was supported by the Spanish National Plan for Scientific Research and Innovation through research grants PERSEO (CTM2007-28925- E/MAR) and TERRIFIC (CTM2014-53582-R). D.C., B.S., and J.R. received financial support from the French National Research Agency through project ANR-10-BLAN1709 PHYTBACK.

\section{Literature Cited}

Banavar, J. R., J. Damuth, A. Maritan, and A. Rinaldo. 2002. Supplydemand balance and metabolic scaling. Proceedings of the National Academv of Sciences of the USA 99:10506-10509.

Bec, B., Y. Collos, A. Vaquer, D. Mouillot, and P. Souchu. 2008. Growth rate peaks at intermediate cell size in marine photosynthetic picoeukaryotes. Limnology and Oceanography 53:863-867.

Blueweiss, L., H. Fox, V. Kudzma, D. Nakashima, R. Peters, and S. Sams. 1978. Relationships between body size and some life history parameters. Oecologia (Berlin) 37:257-272.

Brown, J. H., J. F. Gillooly, A. P. Allen, V. M. Savage, and G. B. West. 2004. Toward a metabolic theory of ecology. Ecology 85:1771-1789.

Burmaster, D. E. 1979. The continuous culture of phytoplankton: mathematical equivalence among three steady-state models. American Naturalist 113:123-134.

Caperon, J. 1968. Growth response of Isochrysis galbana to nitrate variation at limiting concentrations. Ecology 49:886-872.

Chen, B., and H. Liu. 2010. Relationships between phytoplankton growth and cell size in surface oceans: interactive effects of temperature, nutrients, and grazing. Limnology and Oceanography 55: 965-972.

DeLong, J. P., J. G. Okie, M. E. Moses, R. Sibly, and J. H. Brown. 2010. Shifts in metabolic scaling, production, and efficiency across major evolutionary transitions of life. Proceedings of the National Academv of Sciences of the USA 107:12941-12945.

Droop, M. R. 1968. Vitamin B12 and marine ecology. IV. The kinetics of uptake, growth and inhibition in Monochrysis lutheri. Journal of the Marine Biological Association of the United Kingdom 48:689-733.
Edwards, K. F., M. K. Thomas, C. A. Klausmeier, and E. Litchman. 2012. Allometric scaling and taxonomic variation in nutrient utilization traits and maximum growth rate of phytoplankton. Limnology and Oceanography 57:554-566.

Falkowski, P. G., and M. J. Oliver. 2007. Mix and match: how climate selects phytoplankton. Nature Reviews Microbiology 5:813-819.

Fenchel, T. 1973. Intrinsic rate of natural increase: the relationship with body size. Oecologia (Berlin) 14:317-326.

Field, C. B., M. J. Behrenfeld, J. T. Randerson, and P. G. Falkowski. 1998. Primary production of the biosphere: integrating terrestrial and oceanic components. Science 281:237-240.

Finkel, Z. V., J. Beardall, K. J. Flynn, A. Quigg, T. A. V. Rees, and J. A. Raven. 2010. Phytoplankton in a changing world: cell size and elemental stoichiometry. Journal of Plankton Research 32:119-137.

Grover, J. P. 1991. Resource competition in a variable environment: phytoplankton growing according to the variable-internal-stores model. American Naturalist 138:811-835.

Hain, M. P., D. M. Sigman, and G. H. Haug. 2014. The biological pump in the past. Pages 485-517 in H. Holland and K. Turekian, eds. Treatise on geochemistry. Vol. 8. The oceans and marine geochemistry. 2nd ed. Elsevier, Amsterdam.

Hollowed, A. B., M. Barange, R. J. Beamish, K. Brander, K. Cochrane, K. Drinkwater, M. G. G. Foreman, et al. 2013. Projected impacts of climate change on marine fish and fisheries. ICES Journal of Marine Science 5:1023-1037.

Kempes, C. P., S. Dutkiewicz, and M. J. Follows. 2012. Growth, metabolic partitioning, and the size of microorganisms. Proceedings of the National Academv of Sciences of the USA 109:495500.

Kriest, I., and A. Oschlies. 2007. Modelling the effect of cell-sizedependent nutrient uptake and exudation on phytoplankton size spectra. Deep-Sea Research I 54:1593-1618.

Litchman, E., C. A. Klausmeier, O. M. Schofield, and P. G. Falkowski. 2007. The role of functional traits and trade-offs in structuring phytoplankton communities: scaling from cellular to ecosystem level. Ecology Letters 10:1170-1181.

Litchman, E., C. A. Klausmeier, and K. Yoshiyama. 2009. Contrasting size evolution in marine and freshwater diatoms. Proceedings of the National Academv of Sciences of the USA 106:26652670.

Marañón, E. 2015. Cell size as a key determinant of phytoplankton metabolism and community structure. Annual Review of Marine Science 7:241-264.

Marañón, E., P. Cermeño, D. C. López-Sandoval, T. RodríguezRamos, C. Sobrino, M. Huete-Ortega, J. M. Blanco, and J. Rodríguez. 2013. Unimodal size scaling of phytoplankton growth and the size dependence of nutrient uptake and use. Ecology Letters 16:371-379.

Peters, R. H. 1983. The ecological implications of body size. Cambridge University Press, Cambridge.

Raven, J. A. 1994. Why are there no picoplanktonic $\mathrm{O}_{2}$ evolvers with volumes less than $10^{-19} \mathrm{~m}^{3}$ ? Journal of Plankton Research 16:565580.

Sal, S., L. Alonso-Sáez, J. Bueno, F. C. García, and Á. López-Urrutia. 2015. Thermal adaptation, phylogeny, and the unimodal size scaling of marine phytoplankton growth. Limnology and Oceanography 60:1212-1221.

Savage, V. M., J. F. Gillooly, J. H. Brown, G. B. West, and E. L. Charnov. 2004. Effects of body size and temperature on population growth. American Naturalist 163:429-441.

Verdy, A., M. J. Follows, and G. Flierl. 2009. Optimal phytoplankton cell size in an allometric model. Marine Ecology Progress Series 379: $1-12$. 
West, G. B., J. H. Brown, and B. J. Enquist. 1997. A general model for the origin of allometric scaling laws in biology. Science 276:122126.

Wirtz, K. W. 2011. Non-uniform scaling in phytoplankton growth rate due to intracellular light and $\mathrm{CO}_{2}$ decline. Journal of Plankton Research 33:1325-1341.
Zwietering, M. H., I. Jongenburger, F. M. Rombouts, and K. van 't Riet. 1990. Modelling of the bacterial growth curve. Applied and Environmental Microbiology 56:1875-1881.

Associate Editor: Spencer R. Hall Editor: Alice A. Winn

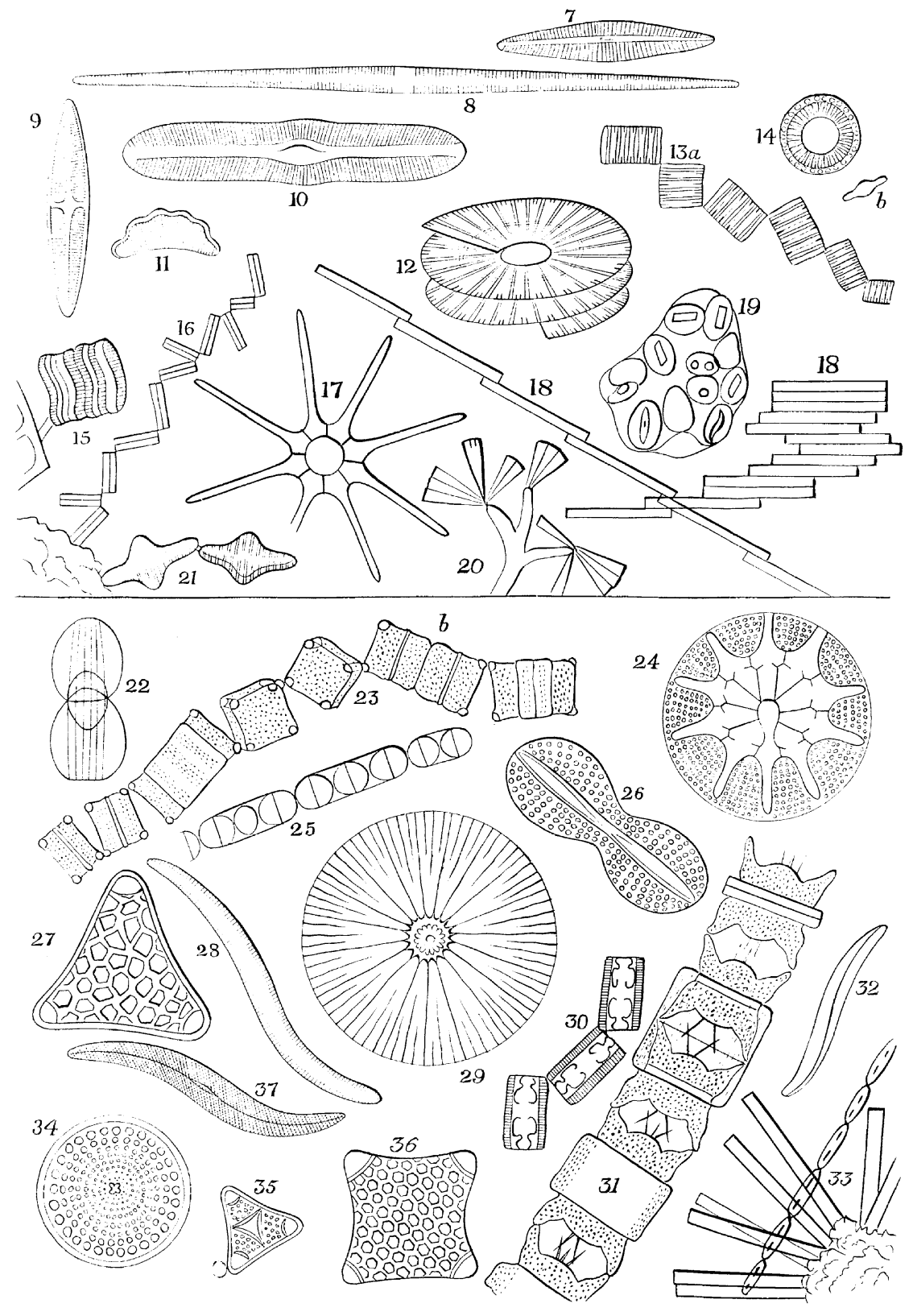

"Diatoms, -Fresh-water. 7, Navicula; 8, Nitschia; 9, Stauroneis; 10, Pinnularia; 11, Eunotia triodon; 12, Meridion vernale; 13, Tabellaria flocculosa, — $a$, front view, $b$, side view; 14, Cyclotella Kützingiana, _ $b$, side view; 15, Acnanthes; 16, Diatoma flocculosum; 17 , Asterionella; 18, Bacillaria paradoxa; 19, Mastogloia; 20, Licmophora; 21, Odontidium. . . Diatoms, —Marine Forms. 22, Amphiprora; 23, Amphitetras, forming a zigzag chain, $-a$, a frustule about to divide into two, $b$, two frustules newly formed but not yet separated; 24 , Asteromphalus, a beautiful deep-sea form, taken from below 2,000 fathoms in the sea of Kamschatka; 25, Podosira; 26, Navicula didyma; 27, Triceratium; 28, Nitschia; 29, Arachnoidiscus; 30, Grammatophora; 31, Biddulphia, - $a$, two frustules, still enclosed by the "connecting membranes," $b$, “connecting membrane," widening previous to self-division; 32, Pleurosigma; 33, Synedra; 34, Cosclinodiscus; 35, Triceratium; 36, Amphitetras." From “Desmids and Diatoms” by L. W. Bailey (The American Naturalist 1867, 1:505-517). 